\title{
LAS TRES IDEAS FUNDAMENTALES DE JOSÉ MARTÍ PARA LA LIBERACIÓN NACIONAL: MORA- LIDAD, JUSTICIA Y LIBERTAD
}

\author{
Jesús A. MARTíNEZ GÓMEZ \\ Centro Universitario "José Martí Pérez. Sancti Spiritus, Cuba
}

\begin{abstract}
RESUMEN: En el trabajo se abordan las tres ideas fundamentales en que basó José Martí su proyecto de liberación nacional para Cuba, así como el alcance internacional que pretendió dar al mismo buscando el necesario equilibrio del mundo.

PALABRAS CLAVE: Idea, Moralidad, Justicia y Libertad.

ABSTRACT: This work speaks about the José Marti's three fundamental ideas in which he based his project of national liberation for Cuba likewise the international reach he pretended to give to it looking for the necessary balance of the world

KEYWORDS: Idea, Morality, Justice and Freedom.
\end{abstract}

José Martí es el hombre más universal del siglo XIX cubano. No fue solo un gran político, escritor, profesor, orador, periodista y poeta; su vida fue mucho más que eso porque la dedicó a una tarea trascendental: la liberación de su pueblo. Su proyecto redentor se articuló a través de tres ideas básicas: moralidad, justicia y libertad.

El héroe cubano vivió convencido de que no hay obra humana que pueda llevarse felizmente a término, y mucho menos perdurar, si no se basa en sólidos principios y valores morales. Eso explica que la prédica moral haya estado presente en su quehacer político práctico y literario. Vivió y murió como saben hacer los grandes, dejándonos una vida pletórica de enseñanzas y de ejemplos, y todo lo que escribió está bañado de inquietudes morales en las que se evidencia su constante preocupación por el valor de la virtud y el perfeccionamiento humano.

Es difícil encontrar un escrito suyo donde no esté presente una sentencia moral acompañada de una reflexión ética. Tampoco resulta fácil encuadrar su conciencia 
moral dentro de una corriente ética de pensamiento, pues bebió de muchas fuentes y no encasilló sus ideas morales en los marcos rígidos de una filosofía o concepción del mundo. Creador por excelencia, le imprimió el sello de su individualidad a todo lo que hizo y rechazó seguir servilmente doctrina alguna. Eso sí, fue el consagrado de una causa: lograr la independencia de Cuba y Puerto Rico e impedir que perdieran la suya las demás Antillas y las jóvenes repúblicas latinoamericanas. A ella dedicó toda la fuerza de su ingenio y entereza moral.

Sus ideas morales no se formaron al fragor del ejercicio académico, en el espacio fijo de una cátedra - aunque en ocasiones se dedicó a ese tipo de labor-, sino en el transcurso de una vida dedicada a la realización de un ideal. Ellas fueron las que le permitieron sostener el peso de la importante tarea histórica de organizar y llevar a vías de hecho una guerra que consideró necesaria, pese a los malestares de un cuerpo que quedó para siempre resentido y agonizante por las secuelas del presidio. Eso explica la fortaleza de su espíritu, que lo mantuvo siempre firme en los proyectos, y la preocupación constante por dotar de contenido moral las acciones revolucionarias.

El proyecto emancipador martiano también estuvo presidido por otra idea básica: la de justicia. Martí concibe la necesidad de la guerra de liberación como acto de justicia encaminado a reivindicar el derecho de su pueblo a ser independiente, y como el principio de un programa de amplias transformaciones sociales encaminado a hacer realidad los derechos de sus compatriotas a una vida mejor y más digna, es decir, a la realización de lo que hoy llamaríamos tres generaciones de derechos humanos: civiles y políticos; económicos, sociales y culturales; y al desarrollo de los pueblos.

Dentro del conjunto de derechos que pretende reivindicar con la realización de su programa de emancipación nacional, Martí destaca la libertad. Entiende que ésta permitiría al hombre liberarse doblemente: en el plano individual y colectivo. En el primero, de la tiranía de los instintos, los convencionalismos sociales y de todo lo que le impida crecer y ganar en humanidad con el ejercicio de la libertad; y en el segundo, de la dependencia de una sociedad de otra, de la tiranía del colonialismo que obstaculizaba la prosperidad de las naciones coartando la realización de la persona humana.

En la formación de sus ideas revolucionarias se aprecia la influencia del pensamiento moderno, y sobre todo de la reelaboración nacional del mismo por el padre José Agustín Caballero y sus discípulos Félix Varela, José Antonio Saco, y José de la Luz y Caballero, a quien prefirió. Por otra parte, del cristianismo que, 
interpretado de forma muy particular, fue siempre un valuarte firme de sus ideas morales, de redención y de justicia social.

\section{MORALIDAD}

Desde muy joven Martí analiza el bien en el marco de sus preocupaciones patrióticas. Cuando cae preso por sus ideales a la edad de 16 años, le dice a su madre: "Mucho siento estar metido entre rejas; -pero de mucho me sirve mi prisión.- Bastantes lecciones me ha dado para mi vida, que auguro que ha de ser corta, y no las dejaré de aprovechar"1. Durante los seis meses que pasó en el presidio reflexionó todo el tiempo sobre la idea del bien, dándonos a conocer sus preocupaciones años más tarde en la obra El presidio políticos en Cuba. Ya entonces se inclina hacia la idea de la concepción trascendente del bien, es decir, concibe el bien no sólo para hoy y para esta vida sino para el futuro y para la eternidad, lo que explica su sentencia de que "la noción del bien flota sobre todo, y no naufraga jamás" ${ }^{2}$.

Buscando dar concreción a esa trascendencia, nos dice que "Dios existe (...) en la idea del bien, que vela el nacimiento de cada ser, y deja en el alma que se encarna en él una lágrima pura. El bien es Dios. La lágrima es la fuente de sentimiento eterno"3. De esta forma, Martí estima que el sentimiento del bien es de origen divino, y en cuanto tal, intrínseco a cada ser que nace a imagen y semejanza del Creador. Por eso en uno de sus apuntes escribe que han muerto y morirán muchas religiones, pero no el "Dios conciencia, la dualidad sublime del amor y del honor, el pensamiento inspirado de todas las religiones, el germen eterno de todas las creencias, la ley irreformable, la ley fija, siempre soberana de las almas, siempre obedecida con placer, siempre noble, siempre igual; - he aquí la Idea Poderosa y fecunda que no ha de perecer, porque renace idéntica con cada alma que surge a la luz; - he aquí la única cosa verdadera, porque es la única cosa por todos reconocida; - he aquí el eje del mundo moral; - he aquí a nuestro Dios omnipotente y sapientísimo"4.

Y, ¿quién es ese Dios conciencia? Es "el hijo del Dios que creó, que es el único lazo visible unánimemente recibido, unánimemente adorado, que une a la

\footnotetext{
${ }^{1}$ MArTí, J. "Carta a su madre", La Habana, 10 de noviembre (1869). Obras Completas, Op. cit., t.1, p. 40.

2 MARTí, J. "El presidio político en Cuba”. Obras Completas, Op. cit, t. 1, p. 52.

${ }^{3}$ Ibidem, p. 45.

4 José MARTí: "Cuadernos de apuntes", Op. cit., p. 28.
} 
humanidad impulsada con la divinidad impulsora"5. La conciencia moral del hombre, los ideales del bien, se han encarnado en el Dios hombre, Jesús de Nazaret. El es el modelo de corrección moral humana, algo así como el arquetipo de conciencia práctica al que los hombres deben rendir culto para que el bien no pierda la pureza necesaria para vencer al mal.

José Martí ve en las creencias un medio magnificar la virtud ${ }^{6}$. Considera que la vida del hombre "sería una invención repugnante y bárbara, si estuviera limitada a la vida en la tierra" " y que la fe religiosa ayuda al perfeccionamiento moral porque "la creencia natural en los premios y castigos y en la existencia de otra vida (...) sirve de estímulo a nuestras buenas obras, y de freno a las malas" ${ }^{\text {". }}$. De ahí que sea categórico cuando expresa: "Un pueblo irreligioso morirá, porque nada en él alimenta la virtud. Las injusticias humanas disgustan de ella; es necesario que la justicia celeste las garantice"".

Sin embargo, Martí no se queda en la idea de la necesidad de la religión para la moralidad como hizo Kant ${ }^{10}$, pues sostiene también que la moral es la base de las buenas religiones ${ }^{11}$. A las religiones o interpretaciones de ella que limitan la vida humana, atentando contra la naturaleza y el crecimiento libre de la espiritualidad del hombre, las rechaza. Por eso dice al "Hombre del campo": "Ese Dios que regatea, que vende la salvación, que todo lo hace en cambio de dinero, que manda las gentes al infierno si no le pagan, y si le pagan las manda al cielo, ese Dios es una especie de prestamista, de usurero, de tendero"12. Y lo alerta: “¡No, amigo mío, hay otro Dios!"13.

Martí cree en el Cristo de los evangelios por "la pureza de su doctrina moral", pureza que debe servir de inspiración al hombre para que pueda hacer el bien con

5 Ibidem.

${ }^{6}$ Cf. Ibidem.

${ }^{7}$ Martí, J. "El Poema del Niagara”, Op. cit., p. 236.

${ }^{8}$ MARTí, J. "Fragmentos", Op. cit., p. 392.

${ }^{9}$ Ibidem.

${ }^{10}$ En concreto Kant trata el tema cuando analiza "los postulados de la razón práctica", entre los que sitúa los conceptos de inmortalidad y Dios. Vid. KanT, I (1973). Critica de la razón práctica. La Habana: Editorial de Ciencias Sociales, Cap. II, Epíg. 4 y 5, pp. 558-567.

11 Martí, J. "Fragmentos”, Op. cit., p. 392.

12 MARTí, J. "Hombre del campo". Obras Completas, Op. cit., t. 19, p. 383.

${ }^{13}$ Ibídem. 
la entereza de Aquél, y no caer frente al mal. En este sentido predica que una de las cualidades morales que más dignifica a quien hace el bien, es el desinterés. Si éste falla, se pierde la preocupación genuina por el ser humano que es la que debe regir la realización del acto moral. Esto explica sus sentenciosas palabras: "el hombre que hace el bien para que le estimen la bondad, o se cansa de hacerlo en cuanto no se la estiman, no es bueno de veras" $"$.

Con el interés aflora el egoísmo que compromete la realización del bien en sí, siempre altruista en la concepción moral martiana. "Los intereses creados son respetables-advierte-, en tanto que la conservación de estos intereses no daña a la gran masa común" ${ }^{\prime 15}$. Y en este sentido es que pensamos debe interpretarse el llamamiento martiano a actuar con desinterés: a no dejar que el egoísmo del acto interesado termine estropeando la finalidad altruista que debe inspirar las obras buenas para que perduren. Por tal razón manifiesta que el desinterés "es la virtud que funda y salva" 16 " "bien mirado es el modo mejor de servir el interés"17.

La distribución del bien moral es mirada por Martí en los marcos de un utilitarismo altruista. Reconoce que es "preferible el bien de muchos a la opulencia de pocos" 18 y que "atender al bien general es favorecer y acelerar el propio"19, pero no sólo porque considere que el interés común comprende también nuestras aspiraciones particulares, y que al ayudar al bienestar humano se está contribuyendo al propio, sino porque más allá de esto, con el sólo acto de beneficiar a los demás sin pensar en ventajas personales, el hombre se hace bueno $\mathrm{y}$ crece.

Esta concepción del bien estuvo presente en su proyecto emancipador, alejado de odios y egoísmos, y explica por qué sus reflexiones sobre la dignidad, la virtud,

${ }^{14}$ Martí, J. "Cuadernos de apuntes", Op. cit, p. 378.

15 MARTí, J. “'El proletario' de Castillo Velasco. El papel barato. La utilidad del sistema prohibitivo". Revista Universal, México, 12 de octubre de 1875. Obras Completas, Op. cit., t. 6, p. 346.

16 MARTí, J. (1993). "Carta a Rafael Serra”, [Nueva York, mayo], de 1889. Epistolario. La Habana: Centro de Estudios Martianos y Editorial de Ciencias Sociales, t. 2, p. 107.

17 Martí, J. "Carta al General Máximo Gómez", Nueva York, diciembre de 1883. Obras Completas, Op. cit., t. 9, p. 479.

18 MARTí, J. “"El proletario' de Castillo Velasco. El papel barato. La utilidad del sistema prohibitivo”, Op. cit., p. 346.

${ }^{19}$ MARTí, J. "Carta a Manuel Mercado”, La Habana, 22 de enero de 1877. Epistolario, Op. cit., t. 1, p. 65 . 
el sacrificio y el deber hayan estado guiadas siempre por un único sentimiento: el amor.

Martí concibe el proyecto revolucionario a partir del valor de la dignidad. Comprende que "ese respeto a la persona humana (...) hace grandes a los pueblos que lo profesan y a los hombres que viven en ellos", pues sin él "los pueblos son caricaturas, y los hombres insectos" 20 . Avizora que en la dignidad se concentra la fuerza moral del hombre, y que "es como la esponja: se la oprime, pero conserva siempre su fuerza de tensión",21, por lo que todo lo que no sea compatible con ella, "caerá" 22 .

Vivió con el convencimiento de que el hombre con su conducta debe hacer real el merecimiento de ese respeto, eligiendo hacer el bien y no el mal, y ayudando a los demás. "En la mejilla-nos dice- ha de sentir todo hombre verdadero el golpe que reciba cualquier mejilla de hombre" ${ }^{23}$. Por eso combate las ideas racistas de la época y la inhumana práctica de la esclavitud.

De niño, cuando en una ocasión visitaba el campo con su padre, presenció un hecho que lo marcaría para siempre, reflejándolo años más tarde en sus Versos sencillos:

Rojo, como en el desierto,

Salió el sol al horizonte:

Y alumbró a un esclavo muerto,

Colgado a un seibo del monte.

Un niño lo vio: tembló

De pasión por los que gimen:

¡Y, al pie del muerto, juró

Lavar con su vida el crimen! ${ }^{24}$

${ }^{20}$ MARTí, J. “Carta a la República”, Honduras, 14 de agosto de 1886. Obras Completas, Op. cit., t. 8, p. 20.

21 MarTí, J. Folleto "Guatemala", escrito en 1877 y publicado en México en 1878. Obras Completas, Op. cit., t. 7, p. 140.

${ }^{22}$ Martí, J. "Cartas de Martí”. La Nación, Buenos Aires, 24 de julio 1885. Obras Completas, Op. cit., t. 10, p. 259.

${ }^{23}$ MARTí, J. "Discurso en el Liceo Cubano", Tampa, 26 de noviembre 1891. Obras Completas, Op. cit., t. 4, p. 270.

${ }^{24}$ MARTí, J. "Versos sencillos", 1991. Obras Completas, Op. cit., t. 16, pp. 106-107. 
A lo que añade su conocida sentencia poética: “ ¡La esclavitud de los hombres/ Es la gran pena del mundo!"25.

Para Martí "dignidad del hombre es su independencia"26, de ahí que todo hombre tenga el deber de extender su libertad a los demás ${ }^{27}$. "Hombre es más que blanco-advierte-, más que mulato, más que negro" 28 porque "sobre las razas (...) está el espíritu esencial humano que las domina y unifica" 29 . Estas ideas encontraron especial reflejo en su ideal libertario, llevándolo a concebir la necesidad de que "la ley primera de nuestra república sea el culto de los cubanos a la dignidad plena del hombre" 30 .

El Apóstol cubano no concibe la vida del hombre sin la lucha constante por el mejoramiento y la perfección de la humanidad. Es a través de esa lucha "que el hombre elabora su dicha y contribuye a la de los demás" ${ }^{31}$. "La vida está en la compañía y el sacrificio" ${ }^{32}$, dice, porque "No se tiene el derecho del aislamiento: se tiene el deber de ser útil" ${ }^{33}$. Combate a los que en su tiempo servían con su pluma al dinero y no al deber ${ }^{34}$, porque "el verdadero hombre no mira de qué lado se vive mejor, sino de qué lado está el deber" ${ }^{35}$.

${ }^{25}$ Ibidem, p. 112.

${ }^{26}$ MARTí, J. "Carta a Carmen Mantilla", [Cabo Haitiano], 9 de abril [de 1895]. Epistolario, Op. cit., t. 5, p. 150.

${ }^{27}$ MARTí, J. "Las elecciones del domingo.-La oposición no fue a votar.-Casillas tristes y alameda animada.-Crítico novel.-Honrado artículo". Revista Universal, México, 29 de junio de 1875. Obras Completas, Op. cit., t. 6, p. 247.

${ }^{28}$ MARTí, J. "Mi raza”. Patria, Nueva York, 16 de abril de 1893. Obras Completas, Op. cit., t.2, p. 299.

${ }^{29}$ MArTí, J. "La República Argentina en los Estados Unidos”. La Nación, Buenos Aires, 4 de diciembre de 1887. Obras Completas, Op. cit., t. 7, p. 331.

${ }^{30}$ Martí, J. "Discurso en el Liceo Cubano", Tampa, 26 de noviembre de 1891. Obras Completas, Op. cit., t. 4, p. 270.

31 Martí, J. "Los lunes de 'La liga'”. Patria, Nueva York, 26 de marzo de 1892. Obras Completas, Op. cit., t. 5, p. 254

${ }^{32}$ Martí, J. "En casa". Patria, Nueva York, 8 de septiembre de 1894. Obras Completas, Op. cit., t. 5 , p. 436 .

33 MARTí, J. "El articulo de Gostkowski.-La juventud buena y la torpe.-Páginas de filosofía". Revista Universal, México, 21 de septiembre de 1875. Obras Completas, Op. cit., t. 6, p. 331.

${ }^{34}$ MARTí, J. "Fragmentos". Obras Completas, Op. cit., t. 22, p. 14.

${ }^{35}$ MARTí, J. "Discurso en conmemoración del 10 de Octubre de 1868", en Hardman Hall, Nueva York, 10 de octubre de 1890. Obras Completas, Op. cit., t. 4, p. 247. 
Ve el porvenir del ser humano estrechamente ligado al cumplimiento del deber. Según su concepción, al devenir instrumento del deber, el hombre se hace hombre $^{36}$, que "es algo más que ser torpemente vivo: es entender una misión, ennoblecerla y cumplirla" ${ }^{\prime 37}$. En este aspecto sus ideas apuntan al planteamiento kantiano de que deber es poder, pues entiende que "ver un deber y no cumplirlo es faltar a él" 38 . Y si al deber se falta, dice, es porque "no se entendió con toda pureza, sino con la liga de las pasiones menores, o no se ejercitó con desinterés y eficacia" ${ }^{39}$.

Entiende que "no hay más que una raza inferior: la de los que consultan, antes que todo, su propio interés, bien sea el de su vanidad o el de su soberbia o el de su peculio: -ni hay más que una raza superior: la de los que consultan, antes que todo, el interés humano" ${ }^{40}$. Sin desinterés la práctica del deber degenera en egoísmo y nunca llega a ser virtud. El interés propio hace que pierda fuerza moral el deber porque su "fuerza está en el sacrificio"41.

El sacrificio implica un desprendimiento de sí que se entrega a los demás, y logra hacerse regularmente si el hombre se propone superar el egoísmo. De acuerdo a su visión, el "egoísmo era la nota de los tiempos antiguos",42, mientras que el "humanismo (el altruismo, la abnegación, el sacrificio de sí por el bien de otros, el olvido de sí) es la nota de los tiempos modernos"43; y de que el mal es causado por el egoísmo ${ }^{44}$, que es a su vez "consecuencia de la riqueza" $"$. Esto lo

${ }^{36}$ MARTí, J. "El Liceo Hidalgo. Monumento. Vuelta a las escuelas. Empresa patriótica. Teatro mexicano". Revista Universal, México, 11 de mayo de 1875. Obras Completas, Op. cit., t. 6, p. 198.

${ }^{37}$ MARTí, J. "El articulo de Gostkowski.-La juventud buena y la torpe.-paginas de filosofía". Revista Universal, México, 21 de septiembre de 1875. Obras Completas, Op. cit., t. 6, p. 332.

${ }^{38}$ MARTí, J. "Fragmentos". Obras Completas, Op. cit., t. 22, p. 77.

${ }^{39}$ MARTí, J. "Discurso en conmemoración del 10 de Octubre de 1868", en Hardman Hall, Nueva York, 10 de octubre de 1890. Obras Completas, Op. cit., t. 4, p. 247.

${ }^{40}$ MARTí, J. “Discurso en honor de Fermín Valdés Domínguez”, Salón Jaeger’s, Nueva York, 24 de febrero de 1894, Obras Completas, Op. cit., t. 4, p. 325.

41 MArTí, J. "El lenguaje reciente de ciertos autonomistas". Patria, Nueva York, 22 de septiembre de 1894. Obras Completas, Op. cit., t. 3, p. 265.

${ }^{42}$ Martí, J. "Cuadernos de apuntes". Obras Completas, Op. cit., t. 21, p. 162.

${ }^{43}$ Ibidem.

${ }^{44}$ Cf. Martí, J. "Fragmentos”. Obras Completas, Op. cit., t. 22, p. 96.

45 Cf. MARTí, J. "Escasez de noticias electorales. Diputados noveles. Comercio e industria. Inteligencia de creación y de aplicación. Teófilo Gautier”. Revista Universal, México, 14 de julio de 1875. Obras Completas, Op. cit., t. 6, p. 270. 
lleva a razonar que "si los gobiernos se hacen egoístas, y los pueblos ricos se apegan a su riqueza y obran como avaros viejos, la humanidad es en cambio perpetuamente joven”46 dando a entender que el pensamiento humanista está por encima de las mezquindades del hombre, y gracias a él, que no envejece, sobrevive la humanidad a todos los vicios que amenazan con destruirla. De ahí su tan categórica sentencia: "El egoísmo es la mancha del mundo, y el desinterés su sol" ${ }^{47}$.

Sobre la base de estas ideas desarrolla su concepción de la virtud, que fue un pilar muy importante dentro de su programa revolucionario. Fue conciente de que "la virtud es costosa, y el espíritu humano la demora y la esquiva, aunque en las horas supremas sea capaz de ella"48. La virtud se levanta contra los vicios humanos, haciéndolos aún mucho más visibles" ${ }^{49}$; por eso con "cada virtud que luce, se encienden todos los vicios que la combaten" ${ }^{\text {"50 }}$. Reconoce que el universo moral del hombre alberga la insoluble contradicción entre virtudes y vicios. "Es así la virtud -expresa-, que, distribuida por el universo equitativamente, siempre que en un espacio o localidad determinada falta en muchos, en uno solo se recoge, para que no se altere el equilibrio y venga a padecer la armonía humana" ${ }^{, 51}$. Por tal razón, le atribuye gran importancia práctica a saber diferenciar en el proceso revolucionario a la virtud verdadera de la aparente, al hombre virtuoso del vicioso disfrazado de bueno.

Es tarea difícil hacer esa diferenciación porque la naturaleza buscando "hacer más meritoria la virtud, ha hecho amables y seductores a los que atentan contra ella, y reparte por igual sus dones entre los que corrompen y los que fundan" ${ }^{\text {"52 }}$.

46 MARTí, J. "A La Colonia Española”. Revista Universal, México, 8 de septiembre de 1876. Obras Completas, Op. cit., t. 1, p. 139.

47 MarTí, J. "Discurso en honor de Fermín Valdés Domínguez". Obras Completas, Op. cit., p. 325.

48 Martí, J. "Cartas de Martí”. La Nación, Buenos Aires, 4 de mayo de 1887 Obras Completas, Op. cit., t. 11, p. 171.

49 Cf. Martí, J. "Cartas de Martí". La Nación, Buenos Aires, 9 de mayo de 1885. Obras Completas, Op. cit., t. 10, p 189.

50 Martí, J. "Cartas de Martí”. La Nación, Buenos Aires, 16 y 17 de junio de 1883. Obras Completas, Op. cit., t. 9, p. 404.

51 Martí, J. "Juan Carlos Gómez”. La América, Nueva York, julio de 1884. Obras Completas, Op. cit., t. 8, p. 189.

52 MARTí, J. "Fragmentos”. Obras Completas, Op. cit., t. 22, p. 193. 
Esto lo convence de que se necesitan más virtudes que talentos ${ }^{53}$, y medita sobre la descripción de signos que permitan descubrir a los falsos virtuosos, tales como:

1. No reconocer la virtud de los demás. "Reconocer la virtud es practicarladice. En eso se conoce al que es incapaz de la virtud, -en que no la sabe conocer en los demás" ${ }^{\prime 4}$.

2. Ver con indiferencia el sacrificio que hacen los hombres virtuosos. Con ese sentido parece que expresa: "Quien ve indiferente a su alrededor los dolores de la virtud, sólo como perro castigado o criminal vergonzoso podrá sentarse mañana entre los que gocen del triunfo" ${ }^{\text {. }}$.

3. No mostrar capacidad para el sacrificio, porque el virtuoso sabe que las "virtudes tienen siempre nuevos heroísmos..."

4. Abusar de la virtud, haciendo ostentación de ella a cada paso, porque "la virtud misma, cuando se abusa de ella, llega a ser teatral, antipatriótica e insolente" ${ }^{, 57}$.

5. Desarrollar la virtud en momentos en que ésta favorece a los intereses personales. "La virtud es presumible-plantea-, cuando está del lado del interés, y sólo en el ejercicio de la virtud reside el triunfo" ${ }^{\text {" }}$.

Para Martí, no hay "peor injuria" para el hombre que acreditarse "la virtud que él no posee" ${ }^{, 59}$. Estima que a estos falsos virtuosos se les desenmascara en los momentos de acción revolucionaria, cuando para mantenerse en el cumplimiento del deber se requiere de verdadero sacrificio. En ese sentido asevera que "en los

53 Martí, J. "Canto y dialecto". Patria, Nueva York, 21 de mayo 1892. Obras Completas, Op. cit., t. 1, p. 453.

${ }^{54}$ Martí, J. "Cuadernos de apuntes". Obras Completas, Op. cit., t. 21, p. 379.

55 Martí, J. "La orden de amparo". Patria, Nueva York, 24 de noviembre de 1894. Obras Completas, Op. cit., t. 5, p. 36.

${ }^{56}$ Martí, J. "Los Laurel”. Revista Universal, México, 4 de enero de 1876. Obras Completas, Op. cit., t. 6 , p. 450.

${ }^{57}$ Martí, J. "Fragmentos". Obras Completas, Op. cit., t. 22, p. 15.

58 Martí, J. "Cartas de Martí". La Nación, Buenos Aires, 31 de marzo de 1883. Obras Completas, Op. cit., t. 9, p. 358.

${ }^{59}$ MARTí, J. "Diario de Montecristi a Cabo Haitiano", $1^{\text {ro }}$ de abril de 1895. Obras Completas, Op. cit., t. 19, p. 207. 
grandes instantes de revolución y crisis, basta la voluntad de la virtud, tan tarda siempre en erguirse como segura, para acorralar a los que se disfrazan de ella" ${ }^{\prime 60}$.

En el credo patriótico martiano, la práctica es la forma suprema de demostrar la coherencia moral entre lo que se dice y lo que realmente se piensa. "Hacer, es la mejor manera de decir",61, manifiesta sentencioso, al tiempo que alerta: "antes que lo que conviene hacer, está siempre lo que se debe hacer" "62. La actuación da la clave para saber quien es el hombre verdaderamente revolucionario, pues "uno es por lo que hace, no por lo que escribe"63. Por eso ve tanto valor en Jesús de Nazaret, que no escribió pero legó una obra en $\operatorname{actos}^{64}$.

Martí desarrolló sus ideas morales buscando aunar a los verdaderos patriotas y evitar que los vicios humanos y el pesimismo comprometieran el ideal libertario como aconteció en la primera de las gestas independentistas cubanas (1968-1978). También quiso cimentar la acción revolucionaria en la moralidad para evitar que se perdieran en la guerra los valores fundamentales en que se asienta la dignidad humana.

Desde temprano vio que no se puede luchar verdaderamente por el hombre si no se le ama. Esto lo llevó a meditar profundamente sobre la importancia del valor del amor para la tarea de libertar a su patria. Según el héroe nacional cubano, el sacrificio que exige la consagración al deber de la lucha por la independencia sólo lo podrían asumir con dignidad las personas que guiaran su vida por el amor y no por el odio. El amor, al que llama "sol de la vida", hace bueno al que ama ${ }^{66}$ y es "el modo de crecer" $"$.

${ }^{60}$ MARTí, J. (1983). "Correspondencia particular de El Partido Liberal”, 4, 5, 6 de noviembre de 1886. Otras Crónicas de Nueva York, 2da. edición, Editorial de Ciencias Sociales, pp. 66-67.

${ }^{61}$ Martí, J. "Propósitos". Revista Venezolana, Caracas, 1ro. de julio de 1881. Obras Completas, Op. cit., t. 7, p. 197.

${ }^{62}$ MARTí, J. "Carta a Manuel Mercado”, Veracruz, 1ro. de enero de 1877, Epistolario, Op. cit., t. 1, p. 61 .

${ }^{63}$ MArTí, J. "Carta a César Zumeta”, [Nueva York, 1894]. Epistolario, Op. cit., t. 4, p. 254.

${ }^{64}$ Cf. Martí, J. "Cuaderno de Apuntes”. Obras Completas, Op. cit., t. 21, p. 370.

${ }^{65}$ Martí, J. “Otras poesías”. Obras Completas, Op. cit., t. 17, p. 318.

${ }^{66}$ Martí, J. "Discurso en Hardman Hall”, Nueva York, 31 de enero de 1893. Obras Completas, Op. cit., t. 4, p. 310 .

67 MARTí, J. "Discurso para honrar la memoria del poeta Alfredo Torroella", Liceo de Guanabacoa, 28 de febrero de de 1879. Obras Completas, Op. cit., t. 5, p. 84. 
Para Martí, en el amor "está la salvación" y "el mando", y, por tanto, sin él no tendrían sentido ni la amistad ni el patriotismo ${ }^{68}$. Cree que a diferencia del odio, que "no construye" ${ }^{69}$, con el amor "renace la esperanza" seguro de felicidad y gobierno entre los hombres", . Por eso llama "asesino alevoso" a quien con el pretexto de dirigir a las "generaciones nuevas", predica "el evangelio bárbaro del odio" $" 72$.

Sus convicciones acerca de la necesidad de desarrollar la virtud del amor calaron profundo en su ideal revolucionario. Medita todo el tiempo sobre la forma más humana de llevar a cabo la liberación del país. A la guerra se va por no encontrarse otra alternativa para reivindicar la dignidad de un pueblo que la ha visto pisoteada y perdida por el status colonial a que ha estado sometido durante siglos. Por tanto, precisa: "Esta no es la revolución de la cólera. Es la revolución de la reflexión" $" 73$.

Se acoge al criterio de que el odio y los rencores atentarían contra la viabilidad del proceso revolucionario y su sentido profundamente humanista. Evocando la guerra anterior de 1968, dice que no está en el ánimo de los que mantienen el ideal de la revolución "permitir que con odios nuevos y desdenes inconvenientes e indignos de nobles corazones, se pierdan los beneficios de aquella convulsión gloriosa y necesaria, porque nada menos que el ejercicio práctico de las grandezas de la guerra fue preciso para olvidar y hacer olvidar la injusticia que la produjo"74. Teniendo en cuenta esto, exhorta a los revolucionarios a aplicar a la política la ley del amor para impedir que los conflictos raciales engendrados por la esclavitud y las rivalidades entre la colonia y la metrópolis hagan degenerar la justicia social

68 MarTí, J. "Dedicatoria en el álbum de Clemencia Gómez", La Reforma, República Dominicana, 12 de septiembre de 1892. Obras Completas, Op. cit., t. 5, p. 21.

${ }^{69}$ Martí, J. "Francia”. La Opinión, Caracas, 1882. Obras Completas, Op. cit., t. 14, p. 496.

${ }^{70}$ Martí, J. "En casa”. Patria, Nueva York, 2 de julio de 1892. Obras Completas, Op. cit., t. 5, p. 385.

${ }^{71}$ MARTí, J. "Los cubanos de Jamaica en el Partido Revolucionario". Patria, Nueva York, 18 de junio de 1892. Obras Completas, Op. cit., t. 2, p. 26.

72 Martí, J. "El Poema del Niágara”, Op. cit., p. 230.

73 Martí, J. "Cuadernos de Apuntes", Op. cit. p. 107.

74 MARTí, J. (1977). "Discurso en conmemoración del 10 de octubre de 1968", en Masonic Temple, Nueva Cork, 10 de octubre de 1888. Discursos del 10 de octubre. La Habana: Editorial de Ciencias Sociales, p. 25-26. 
que se persigue en la venganza y ajustes de cuentas entre negros y blancos, criollos y peninsulares ${ }^{75}$.

Estas ideas suyas alcanzaron continuidad y plena madurez en abril de 1895 , en el Manifiesto de Montecristi, documento en el que planteó que la guerra no es "el insano triunfo de un partido cubano sobre otro, o la humillación siquiera de un grupo equivocado de cubanos" " más temida que útil, (...) sino el producto disciplinado de la resolución de hombres enteros que en el reposo de la experiencia se han decidido a encarar otra vez los peligros que conocen, y de la congregación cordial de los cubanos de más diverso origen, convencidos de que en la conquista de la libertad se adquieren mejor que en el abyecto abatimiento las virtudes necesarias para mantenerla"77.

Tampoco es la guerra "contra el español, que, en el seguro de sus hijos y en el acatamiento a la patria que se ganen podrá[n] gozar respetado[s], y aun amado[s], de la libertad que sólo arrollará a los que le salgan, imprevisores, al camino. Ni del desorden, ajeno a la moderación probada del espirita de Cuba, será cuna la guerra; ni de la tiranía" ${ }^{78}$... Y añade, concluyendo: "En la guerra que se ha reanudado en Cuba no ve la revolución las causas del júbilo que pudiera embargar al heroísmo irreflexivo, sino las responsabilidades que deben preocupar a los fundadores de pueblos" $"$.

$\mathrm{Su}$ proyecto libertario es abiertamente altruista y pudiera ser enmarcado como un eslabón fundamental dentro de una esperanza utópica de alcance holístico:

Todos los árboles de la tierra se concentrarán al cabo en uno, que dará en lo eterno suavísimo aroma: el árbol del amor:- ¡de tan robustas y copiosas ramas, que a su sombra se cobijarán sonrientes y en paz todos los hombres! $!^{80}$

${ }^{75}$ Ibidem.

${ }^{76}$ MArTí, J. "Manifiesto de Montecristi”. Obras Completas, Op. cit., t.4, p. 93.

${ }^{77}$ Ibidem, p. 94.

${ }^{78}$ Ibidem.

${ }^{79}$ Ibídem.

${ }^{80}$ MARTí, J. "Prólogo a Cuentos de hoy de mañana, de Rafael de Castro Palomino". La América, Nueva York, octubre de 1883. Obras Completas, Op. cit., t. 5, p. 103. 


\section{JUSTICIA Y LIBERTAD}

Martí considera que la guerra es un acto de justicia que se encamina a liberar al hombre y a preparar el camino para una paz perpetua que ve en el equilibrio del mundo. Señala que no se pediría a los cubanos sacrificar su vida en una lucha por la independencia política "si con ella no fuese esperanza de crear una patria más a la libertad del pensamiento, la equidad de las costumbres, y la paz del trabajo" ${ }^{\text {" }}$. Para él, la guerra de independencia "es suceso de gran alcance humano, y servicio oportuno que el heroísmo juicioso de la Antillas presta a la firmeza y [...] trato justo de las naciones $[\ldots]$ americanas, y al equilibrio aún vacilante del $[\ldots]$ mundo" $" 82$.

La guerra sin odios haría un servicio a la justicia y libertad universales, propiciando la integración de los pueblos antillanos y en general de América. Martí sabe que " ¡Mil veces la justicia se ha perdido / por la exageración de la violencia!" " 33 , por eso insiste en que sólo se justifica la guerra justa. "Si no excusa la justicia la violencia que se comete en su nombre-plantea-, ésta no desvanece la razón leal de que es exceso" ${ }^{" 4}$. ¿Y qué es la justicia para Martí? Pues "la acomodación del Derecho positivo al natural" ${ }^{15}$. En este punto sigue al iusnaturalismo racionalista moderno, afirmando la tesis de que el hombre es libre por naturaleza y debe luchar siempre que se vea privado del derecho natural a la libertad ${ }^{86}$. Así, sostiene que la guerra de liberación es justa por responder al mandato del derecho natural, por lo que la violencia en ella debe ajustarse a lo que prescribe este derecho y evitar los excesos que la convertirían en injusta, en un mal y no en un bien para la sociedad ${ }^{87}$.

${ }^{81}$ Ibidem, p. 100.

${ }^{82}$ Ibídem, pp. 100-101.

${ }^{83}$ MARTí, J. "Drama indio. Patria y libertad", Guatemala, escrito en 1877 y publicado en México en 1878. Obras Completas, Op. cit., t. 18, p. 159.

84 Martí, J. "Wendell Phillips". La Nación, Buenos Aires, 28 de marzo de 1884. Obras Completas, Op. cit., t. 13, p. 69.

${ }^{85}$ Martí, J. "Los códigos nuevos”, Guatemala, abril de 1877. Obras Completas, Op. cit., t. 7, p. 101.

${ }^{86}$ Cf. MarTí, J. "El general Grant”. La Nación, Buenos Aires, 27 de septiembre de 1885. Obras Completas, Op. cit., t. 13, p. 83.

${ }^{87}$ Cf. MARTí, J. "Bancroft". La Nación, Buenos Aires, 25 de febrero de 1887. Obras Completas, Op. cit., t. 13, p. 312. 
Para Martí queda claro que la moralidad de la acción es garante de su justicia ${ }^{88}$ y que la indiferencia ante las injusticias degrada moralmente a los hombres ${ }^{89}$. Por eso estima que quien quiera conquistar sus derechos deberá estar dispuesto al sacrificio $^{90}$, a la actuación con entereza ${ }^{91}$, pero sin olvidar que "amar es más útil que odiar" ${ }^{\prime 2}$ y que el odio atenta contra la virtud que confiere a la guerra la fuerza moral para mantenerse en el camino de lo justo. En su concepción el derecho a la independencia es un bien social por el que se deberá luchar para bienestar y prosperidad de la nación, y no para saciar los apetitos y ambiciones personales de un grupo de hombres ${ }^{93}$. Opina que la libertad y el derecho no servirían de nada si no son ejercidos por todos ${ }^{94}$ y que es la justicia la que debe garantizar todos los derechos, incluido el de la libertad, para lo que es imprescindible enseñar y educar al hombre.

Sobre el tema de la libertad encontramos en el discurso martiano tres tesis de suma importancia: aprender para ser libre, aprender a ser libre y practicar la solidaridad como garantía de la libertad.

Con respecto a la primera tesis, el héroe cubano sigue a los enciclopedistas franceses en el planteamiento de que a través de la educación, el hombre, que nace fiera, conquista la humanidad subordinando los instintos a la razón. Opina que "en la escala moral de fiera a hombre, hay sus grados, como en la escala zoológica. La victoria está en humillar a la fiera" ${ }^{95}$, por lo que la historia humana no es más "el

${ }^{88}$ Cf. MARTí, J. “Grandes motines de obreros”. La Nación, Buenos Aires, 2 de julio de 1886. Obras Completas, Op. cit., t. 10, p. 451.

${ }^{89}$ Cf. Martí, J. "Cartas de Martí”. La Opinión Política, Montevideo, 1889. Obras Completas, Op. cit., t. 12, p. 251.

${ }^{90}$ MarTí, J. "Circular”, Nueva York, 28 de abril de 1880. Obras Completas, Op. cit., t. 1, p. 146.

${ }^{91}$ MARTí, J. "El cisma de los católicos en Nueva York". El Partido Liberal, México, 14 de abril de 1887; publicado también en La Nación, Buenos Aires, 14 de abril de 1887. Obras Completas, Op. cit., t. 11, p. 146.

${ }^{92}$ Ibídem.

93 Cf. Martí, J. "Cartas de Martí”. La Nación, Buenos Aires, 26 de mayo de 1888. Obras Completas, Op. cit., t. 11, p. 439.

94 Cf. Martí, J. (1985). "Los tiempos se acercan”. El Socialista, México, 11 de junio de 1876. Obras Completas, Edición Crítica. La Habana: Centro de Estudios Martianos, t. 2, p. 274.

95 Martí, J. "Carta de Nueva York". La Opinión Nacional, Caracas, 26 de diciembre de 1881. Obras Completas, Op. cit., t. 9, p. 165. 
tránsito del hombre-fiera al hombre hombre" 96 , en el que el último vence enfrentándose a la fiera y sentando sobre ella un ángel ${ }^{97}$. Esta victoria se logra a través de la educación que hace del hombre "una fiera educada" ", acta para "criar la divinidad que lleva en sí" ${ }^{\prime \prime 9}$.

En el plano socio-político también es preciso aprender para conquistar la libertad a través de la guerra reflexiva, sin odios; y después de conquistada, para mantenerla y hacer efectivo su ejercicio en la república. "Con ser hombres -señala, traemos a la vida el principio de la libertad; y con ser inteligentes tenemos el deber de realizarla" ${ }^{100}$. Advierte que el mejor modo de defender los derechos, incluyendo el de la libertad, "es conocerlos bien" "101, y que, por tanto, la "educación es el único medio de salvarse de la esclavitud"102, o, en otras palabras: "Ser culto es el único modo de ser libres" ${ }^{" 103}$.

También considera necesario aprender a ser libres, aprender la democracia. Refiriéndose a los pueblos de Nuestra América, dice: "Somos libres, porque no podemos ser esclavos: nuestro continente salvaje, y nuestra condición es el dominio propio: pero no sabemos ser libres todavía" ${ }^{, 104}$.

Dio mucho valor a la libertad de conciencia y a la libre expresión. Por eso enfatiza: "La libertad es como el genio, una fuerza que brota de los incógnito; pero el genio como la libertad se pierden sin la dirección del buen juicio, sin las

96 MARTí, J. "Carta de Nueva York". La Opinión Nacional, Caracas, 4 de marzo de 1882. Obras Completas, Op. cit., t. 9, p. 255.

${ }^{97}$ Ibídem.

98 Cf. Martí, J. (1983). "Correspondencia particular de El partido liberal”, México, 4, 5, 6 de noviembre de 1886. Otras crónicas de Nueva York, 2da edición. La Habana: Editorial de Ciencias Sociales, p. 74.

99 Martí, J. "Carta de José Martí”. El Partido Liberal, México, 17 de diciembre de 1891. Obras Completas, Op. cit., t. 12, pp. 503-504.

100 MARTí, J. "Comentario al libro La democracia práctica, de Luis Varela”. Revista Universal, México, 7 de marzo de 1876. Obras Completas, Op. cit., t. 7, p. 347.

${ }^{101}$ Martí, J. “Educación Popular”. Obras Completas, Op. cit., t. 19, p. 376.

102 Ibidem.

103 MARTí, J. "Maestros ambulantes". La América, Nueva York, mayo de 1884. Obras Completas, Op. cit., t. 8, p. 289.

${ }^{104}$ MARTí, J. "Democracia práctica" (Libro nuevo del publicista americano Luis Varela). Revista Universal, México, 7 de marzo de 1876. Obras Completas, Op. cit., t. 4, p. 347. 
lecciones de la experiencia, sin el pacífico ejercicio del criterio" ${ }^{\text {105 }}$. Se percata de que sin la educación de los hombres para que sean entes autónomos, será imposible sostener la libertad de una nación. "La libertad política no estará asegurada previene-, mientras no se asegure la libertad espiritual. Urge libertar a los hombres de la tiranía de la convención, que tuerce sus sentimientos, precipita sus sentidos y sobrecarga su inteligencia con un caudal pernicioso, ajeno, frío y falso" ${ }^{106}$, pues "la conciencia propia y el orgullo de la independencia garantizan el buen ejercicio de la libertad"107. Y no le caben dudas de "que la primera libertad, base de todas, es la de la mente" ${ }^{" 108}$. En el presidio lo descubre ${ }^{109}$, dejando su testimonio cuando escribe: "Nunca como entonces supe cuánto el alma es libre en las más amargas horas de la esclavitud" $"$.

En el pensamiento revolucionario martiano la autonomía personal debe encontrar garantías para su realización en la autonomía política, la cual nunca se podrá lograr copiando modelos teóricos y fórmulas extranjeras. Por eso insiste en que los hombres autónomos son creadores y que el hombre americano debe ser consciente de eso ${ }^{111}$ y esmerarse en conocer los elementos propios del país que ha de gobernar "para llegar, por métodos e instituciones nacidas del país mismo, a aquel estado apetecible donde cada hombre se conoce y ejerce, y disfrutan todos de la abundancia que la naturaleza puso para todos en el pueblo que fundan con su trabajo y defienden con sus vidas"112.

105 Ibídem

${ }^{106}$ MARTÍ, J. “Libros”. Obras Completas, Op. cit., t. 18, p. 290.

107 MARTÍ, J. "El proyecto de instrucción pública. Los artículos de la fe. La enseñanza obligatoria”, Revista Universal, México, 26 de octubre de 1875. Obras Completas, Op. cit., t. 6, p. 351.

108 MARTí, J. "En los Estados Unidos", La Nación, Buenos Aires, 22 de noviembre de 1889. Obras Completas, Op. cit., t. 12, p. 348.

${ }^{109}$ Cf. Vitier, C. (2004). Vida y Obra del Apóstol José Martí. La Habana: Centro de Estudios Martianos, p. 15.

${ }^{110}$ MARTí, J. "El presidio político en Cuba”, Op. cit., p. 54.

111 Cf. MARTí, J. "Comentario al libro La democracia práctica, de Luis Varela”, Op. cit., p. 347.

112 MARTí, J. "El proyecto de instrucción pública. Los artículos de la fe. La enseñanza obligatoria”, Op. cit., p. 351. 
En el credo martiano la fraternidad no es una concesión, sino un deber ${ }^{113}$, y la solidaridad, suprema garantía para la efectividad de la libertad. Plantea que el arte de la libertad consiste en poner el egoísmo al servicio de la virtud ${ }^{114}$, por lo que es deber del hombre libre ayudar a la libertad de los demás. Y no ayudar a que se liberen los que padecen la dominación es faltar a la justicia, virtud moral suprema. "Todo hombre de justicia y honor -señala- pelea por la libertad dondequiera que la vea ofendida, porque es pelear por su entereza de hombre; y el que ve la libertad ofendida y no pelea por ella, o ayuda a los que la ofenden,- no es hombre entero" $"$.Quien no se muestra solidario con los que no tienen libertad "y se niega a trabajar por la libertad de todos", es indigno de su libertad, no la merece ${ }^{116}$ porque la degrada con la inmoralidad de la vileza de ser indiferente ante los dolores humanos ${ }^{117}$.

También se falta a la justicia si después de conquistada la independencia, los gobernantes no ofrecen oportunidades iguales a todos en la república. "Amamos a la libertad-escribe-, porque en ella vemos la verdad. Moriremos por la libertad verdadera; no por la libertad que sirve de pretexto para mantener a unos hombres en el goce excesivo, y a otros en el dolor innecesario. Se morirá por la república después, si es preciso, como se morirá por la independencia primero" ${ }^{118}$. Y es que para Martí no puede haber libertad verdadera sin justicia social, sin el derecho igual de los hombres a los beneficios de la libertad.

Estas ideas suyas presidieron el ideario independentista que personificó. En $L a$ Proclamación del Partido Revolucionario Cubano ${ }^{119}$, el 10 de abril de 1892,

113 MARTí, J. "Beneficio de los sombrereros en huelga. Función en el teatro nacional. Ausencia de los obreros. La huelga inaugura el ejercicio de un derecho. Ayuda y protección". Revista Universal, México, 10 de junio de 1875. Obras Completas, Op. cit., t. 6, p. 227.

${ }^{114}$ MARTí, J. "Descripción de la primera votación de las mujeres en Kansas". La Nación, Buenos Aires. El Partido Liberal, México, 21 de mayo de 1887. Obras Completas, Op. cit., t. 11, p. 187.

115 Martí, J. “Un español”, Patria, Nueva York, 16 de abril de 1892. Obras Completas, Op. cit., t. 4 , p. 391.

116 Cf. MARTí, J. "Cuatro clubes nuevos", Patria, Nueva York, 14 de enero de 1893. Obras Completas, Op. cit., t. 2, p. 199.

117 Cf. Martí, J. "El día de la patria". Patria, Nueva York, 10 de abril de 1893. Obras Completas, Op. cit., t. 4, p. 435.

118 MARTí, J. “¡Vengo a darte patria!”. Patria, Nueva York, 14 de marzo de 1893. Obras Completas, Op. cit., t. 2, p. 255.

119 La Proclamación se produce el 10 de abril de 1892, y el día 16 Martí escribió un artículo dándola a conocer. 
escribe: "Para el servicio desinteresado y heroico de la independencia de Cuba y Puerto Rico se funda el Partido Revolucionario Cubano, y no para la obra fea y secreta de allegarse simpatías por pagos y repartos de autoridad y de dineros. Para la obra común se funda el partido, de las almas magnánimas y limpias" ${ }^{\text {"120 }}$. En carta a Máximo Gómez, de 13 de septiembre de 1892, le habla de "la guerra que el Partido está en la obligación de preparar, de acuerdo con la Isla, para la libertad y el bienestar de todos sus habitantes, y la independencia definitiva de las Antillas" ${ }^{2121}$.

Martí se pasó la mayor parte de su vida peregrinando en el destierro, visitó muchos países de América Latina y el Caribe, y sobre todo vivió 15 años en los Estados Unidos. La vida en este último le permitió afianzar la idea de la necesidad de fundar el liberalismo en la justicia y la solidaridad entre los pueblos ${ }^{122}$. La revolución cubana debía hacerse por justicia y para garantizar la justicia social, no para que un puñado de hombres se enseñoreara del resto de la población del país. Esa fue la conclusión a la cual arribó, partidario siempre de lograr el equilibrio entre las clases y aun entre las naciones del mundo para evitar los excesos que pudieran poner en peligro la verdadera libertad, la libertad justa, imposible de alcanzar sin la práctica de la solidaridad. Esto explica su convencimiento "de que la independencia de Cuba y Puerto Rico no es sólo el medio único de asegurar el bienestar decoroso del hombre libre en el trabajo justo a los habitantes de ambas islas, sino el suceso histórico indispensable para salvar la independencia amenazada de la Antillas libres, la independencia amenazada de la América libre, y la dignidad de la república norteamericana" ${ }^{\prime 23}$.

Persuadido de que la libertad de un pueblo se hace indigna cuando se utiliza para quebrantar la de los demás, estima que se presta un gran servicio al propio pueblo norteamericano impidiendo la ingerencia de los Estados Unidos en los pueblos del Caribe y de América Latina. Un día antes de caer en combate, el 18 de mayo de 1895, escribió a su amigo Manuel Mercado reafirmando sus ideas y el precio que estaba dispuesto a pagar por ellas: “... ya estoy todos los días en peligro

${ }^{120}$ MARTí, J. (1975). "Proclamación del Partido Revolucionario Cubano". Patria, 16 de abril de 1892 en Martí J. El Partido Revolucionario Cubano. La Habana: Editorial de Ciencias Sociales, p. 48.

121 Martí, J. "Carta a Máximo Gómez", 13 de septiembre de 1892, en Martí J. El Partido Revolucionario Cubano, Op. cit., p. 98.

122 Cf. Martí, J. "La crisis y el Partido Revolucionario Cubano". Patria, Nueva York, 19 de agosto de 1893, en Martí J. El Partido Revolucionario Cubano, Op. cit., p. 139.

${ }^{123}$ MARTí, J. "El tercer año del Partido Revolucionario Cubano". Patria, Nueva York, 17 de abril de 1894, en Martí J. El Partido Revolucionario Cubano, Op. cit., p. 158. 
de dar mi vida por mi país y por mi deber - puesto que lo entiendo y tengo ánimos con que realizarlo- de impedir a tiempo con la independencia de Cuba que se extiendan por las Antillas los Estados Unidos y caigan, con esa fuerza más, sobre nuestras tierras de América" ${ }^{24}$.

Martí entendió que debía evitar a tiempo la anexión de los pueblos de Nuestra América "al Norte revuelto y brutal que los desprecia"125, a lo cual se sintió impelido por el conocimiento del peligro que se avecinaba. Lo expresó con mucha claridad: "Viví en el monstruo, y le conozco las entrañas"126.

\section{A MODO DE CONCLUSIONES}

Hombre de pensamiento y acción, pero sobre todo de su tiempo, Martí concibió la liberación nacional cubana sobre la base de las ideas éticas y jurídicas del liberalismo moderno, que interpretó a tono con la época y el lugar donde vivió, y se propuso estar a la altura de la gran tarea histórica. En él, como en otros pensadores cubanos del siglo XIX, se acrisolan los aportes de la filosofía moderna con lo mejor del pensamiento moral cristiano.

No persistió en la abstracción ontológica del bien, por lo general impenetrable, sino en la consistencia de la bondad, que para él fue verdad suprema ${ }^{127}$. Su visión salvadora del bien lo llevó a concebir una ética para la liberación que tomó aspectos de la moralidad de Cristo como modelo para el perfeccionamiento moral del revolucionario, y la idea del deber que concibió como medio indispensable para la trascendencia histórica y la inmortalidad terrena, dotando a su fe en la salvación de un componente revolucionario necesario e imprescindible en el marco de su proyecto emancipador.

A semejanza de Jesús de Nazarét, Martí vio en el sacrificio un medio de purificación y sostén de la virtud; y en la indolencia ante el padecimiento del prójimo, un mal incompatible con la solidaridad en que se debe fundar la dignidad humana para que no caiga frente al egoísmo. Interpretó la justicia con una noción de equilibrio en la que se vertebran aspectos fundamentales del iusnaturalismo moderno con elementos de la ética antigua basada en el mesotes, estimando que en

124 MARTí, J. (1982). “Carta a Manuel Mercado”, 18 de mayo de 1895, en Martí por Martí. La Habana: Editorial Letras Cubanas, p. 361.

125 Ibidem.

126 Ibidem.

${ }^{127}$ Cf. Vitier, M. (2002). Las ideas en Cuba. La filosofía en Cuba. La Habana: Editorial Ciencias Sociales, p. 380. 
ella debe fundarse el derecho a la lucha por la independencia de la patria, que podría degenerar si no se ejercía dentro del marco de la moralidad, ceñido a la virtud del amor. Nunca pretendió valerse de la guerra para pasar cuentas al colonialista, sino hacer justicia. Se debían extirpar los males de la dominación, y sobre todo la dependencia política y jurídica que había estado sustentada en el más cruel de los regímenes socioeconómicos: el de la esclavitud.

Insertó su proyecto de liberación nacional dentro de uno mucho mayor: garantizar la libertad de la las Antillas y contribuir con ella al equilibrio del mundo. Lo dijo muy claramente: "Es un mundo lo que estamos equilibrando"128. Se propuso "evitar, con la vida libre de la Antillas prósperas, el conflicto innecesario entre un pueblo tiranizador de América y el mundo coaligado contra su ambición"129.

Lo que incorporó a su proyecto revolucionario del liberalismo no lo hizo en la proyección que parte del respeto a los derechos individuales, incluyendo las libertades fundamentales, para sobre su base edificar el todo social. Más bien se motivó a buscar el condicionamiento mutuo entre autonomía personal e independencia de la nación, y entre proyecto de felicidad privado y social porque vio que si se inclinaba la balanza hacia cualquiera de los extremos se podían fomentar el egoísmo o el totalitarismo. Lo que pretendió fue garantizar el equilibrio entre derechos civiles y deberes sociales para impedir que el respeto ilimitado a uno de estos condujera a la injusticia. Vivió persuadido de que la libertad y la dignidad son verdaderas cuando son justas.

Su entrega a la idea de redención del hombre es inconcebible sin la fuerza que infundió en él la consagración. La lucha por la independencia tuvo en Martí un objeto sagrado: la Patria. "Lo que yo sí acataré toda mi vida es la voluntad manifiesta de mi tierra, aun cuando sea contraria a la mía"130, señaló, lo que no puede menos que hacernos evocar aquel pasaje de Lucas en el que Jesús dice: "Padre, si quieres, aleja de mí este cáliz: pero no se haga mi voluntad, sino la tuya" 131 .

${ }^{128}$ MARTí, J. "El Alma de la Revolución, y el deber de Cuba en América". Patria, Nueva York, 17 de abril de 1894, en Martí J. El Partido Revolucionario Cubano, Op. cit., p. 157.

${ }^{129}$ Ibídem, p. 158.

${ }^{130}$ Martí, J. "Carta a Ricardo Rodríguez Otero", Nueva York, 16 de mayo de 1886. Obras Completas, Op. cit., t 1, p. 192.

131 SAN LUCAS: 22: 42. 
Valorando la dimensión de su persona, Rubén Darío dijo que "no era José Martí, como pudiera creerse, de los semigenios de que habla Méndez, incapaces de comunicarse con los hombres porque sus alas les levantan sobre las cabezas de éstos, e incapaces de subir hasta los dioses, porque el vigor no les alcanza y aún tiene fuerza la tierra para atraerles. El cubano era 'un hombre'. Más aún; era como debería ser el verdadero superhombre, grande y viril; poseído del secreto de su excelencia, en comunión con Dios y con la naturaleza". ${ }^{132}$

Se sintió llamado al deber desde muy joven y auguró cuál sería su fin, derivando en mucho sus convicciones de la existencia penosa que llevó ${ }^{133}$. Los cubanos lo llamamos el Apóstol de la independencia por encontrar similitud entre el designio de su vida y la de los Apóstoles (del gr., Apostoleus) que viajaron siempre con una misión trascendental y salvífica ${ }^{134}$, iluminando con su prédica el camino que seguirían los demás. Trató de ser coherente y potenció su pensamiento con la acción revolucionaria, convencido de que, para ser cré́ble, el pensamiento del hombre debe quedar plasmado en su conducta ${ }^{135}$. Con su vida atestiguó sus ideas y, al caer, su obra inconclusa trasciende animando a los jóvenes que, en 1953, las retomaron cuando parecía ya olvidada. Fidel lo advirtió en su histórico alegato La historia me absolverá: "Parecía que el Apóstol iba a morir en el año de su centenario, que su memoria se extinguiría para siempre, itanta era la afrenta!"136.

Martí sigue siendo arquetipo de conducta moral y política para los cubanos. Su obra aun no está terminada y su inquebrantable fe en el triunfo y en el mejoramiento humano es un eterno sol para nuestro mundo moral y las ideas de redención y de paz que compartimos con el resto de los pueblos latinoamericanos.

132 DARío, R. (2002). "Los raros". Revista Cubana, julio 1951-diciembre 1952, pp. 478-488, en José Martí y el equilibrio del mundo. La Habana: Editorial Ciencias Sociales, p. 41.

${ }^{133}$ VITIER, M. Op. cit., p. 380.

${ }^{134}$ CePedA, R. (S/A). Lo Ético-Cristiano en la Ética de José Martí. Matanzas (Cuba): Centro de Información y Estudio Augusto Cotto, pp. 102-103.

135 Cf. Martí, J. "Generoso deseo". Patria, Nueva York, 30 de abril de 1892. Obras Completas, Op. cit., t. 1, p. 424.

${ }^{136}$ Castro, F. (1981). La Historia me Absolverá. La Habana: Editorial de Ciencias Sociales, p. 97. 